\title{
Molecular basis of mechanisms of steroid resistance in children with nephrotic syndrome
}

\author{
Monika Świerczewska ${ }^{1 凶}$, Danuta Ostalska-Nowicka², Bartosz Kempisty ${ }^{1,3}$ Michał Nowicki ${ }^{1}$ and \\ Maciej Zabel1,4
}

1Department of Histology and Embryology, Poznan University of Medical Sciences, Poznań, Poland; ${ }^{2}$ Department of Pediatric Cardiology and Nephrology, Poznan University of Medical Sciences, Poznań, Poland; ’ Department of Anatomy, Poznań University of Medical Sciences, Poznań, Poland; 4Department of Histology and Embryology, Wroclaw Medical University, Wrocław, Poland

\begin{abstract}
Steroid therapy, due to a wide range of anti-inflammatory properties of steroids, is a basic field of treatment in many human diseases including the nephrotic syndrome in children. However, not all patients respond positively to therapy which divides them into steroid sensitive (SS) and steroid resistance (SR) individuals. Many potential factors associated with steroid resistance have been identified so far. It seems that genetic factors associated with glucocorticoid receptor a (GRa), the structure of heterocomplex of GR as well as glycoprotein P or cytochrome P450 may play a role in the induction of glucocorticoid resistance. Here we described several of the molecular mechanisms, which can regulate glucocorticoid sensitivity and resistance. Moreover, we presented genetic defects, which can lead to various effects of treatment and, in a longer perspective, enable clinicians to individualize therapies.
\end{abstract}

Key words: nephrotic syndrome, glucocorticoid receptor, steroid resistance, polymorphisms

Received: 18 December, 2012; revised: 15 April, 2013; accepted: 22 July, 2013; available on-line: 01 August, 2013

\section{INTRODUCTION}

Nephrotic syndrome (NS) is the most common kidney disease in childhood. In about $90 \%$ of cases it involves primary glomerulopathy while the remaining $10 \%$ encompass secondary glomerulopathies due to systemic, metabolic or infectious diseases (Banaszak et al., 2011). An idiopathic nephrotic syndrome (INS) is a clinical manifestation of histological variants such as the minimal change nephrotic syndrome (MCNS), in which no significant lesions are detected in renal morphology (52-78\%) (Banaszak et al., 2011; Taraszkiewicz et al,. 2009). The remaining two variants, namely diffuse mesangial proliferation (DMP) and focal segmental glomerulosclerosis (FSGS), do not account for more than $10 \%$ of nephrotic syndrome diagnosed in children (Banaszak et al., 2011).

The treatment of primary NS is based on administration of synthetic glucocorticoids (Banaszak et al., 2011; Jaroniec et al., 2010). Unfortunately, it is not always effective and, therefore, cases of steroid sensitivity can be distinguished, generally associated with MCNS (about $80 \%$ of all children suffering from primary nephrotic syndrome), as well as cases of steroid resistance, linked more frequently to MesPGN or FSGS (characterizing about $20 \%$ of patients) (Banaszak et al., 2011). The frequently employed synthetic glucocorticoids include pred- nisone (encorton), methylprednisolone (medrol, metypred), prednisolone (encortolon).

The action of glucocorticoids may involve genomic and non-genomic mechanisms.

\section{GENOMIC MECHANISMS OF GLUCOCORTICOID ACTIVITY}

Genomic mechanisms of glucocorticoid activity involve mediation of glucocorticoid receptor (GR) function. GR belongs to the family of intracellular nuclear receptors, which also includes receptors for mineralocorticoids, androgens, estrogens and thyroid hormones (Barnes, 1998; Smoak et al., 2004). Two isoforms of human GR, GR $\alpha$ and GR $\beta$, arise due to alternate splicing of a single gene. GR $\alpha$ consists of 777 amino acids, binds hormones and activates genes reacting to glucocorticoids. GR $\beta$, in contrast to $G R \alpha$, contains just 742 amino acids in its C-terminal domain and it does not bind glucocorticoids. The function of GR $\beta$ has not been fully clarified but it may play a role of a negative controller of GR $\alpha$ and may mediate resistance to glucocorticoids during inflammatory response (Barnes, 1998; De Iudicibus et al., 2011; Lu et al., 2004; Smoak et al., 2004) (Fig. 1).

$\mathrm{GR} \alpha$ consists of three domains. Its N-terminal transactivation domain contains a region capable of activating transcription of AF-1 genes. The DNA-binding domain, a highly conserved domain among the nuclear receptors, contains a zinc finger structural motif, which participates in dimerization of the receptor and its translocation to the cell nucleus. The final segment contains the C-terminal domain, responsible for binding of the ligand (Gross et al., 2009; Heitzer et al., 2007; Yang et al., 2012) (Fig. 1). In the cytoplasm, GR is present in its inactive form in a multimeric complex with various proteins, such as heat shock proteins 90 (Hsp90), Hsp70, Hsp56, Hsp40, p23 protein and Src (steroid receptor coactivator). Binding of glucocorticoids causes dissociation of the proteins and the receptor becomes active. The active receptor undergoes translocation to the cell nucleus, dimerization,

e-mail: m_swierczewska@wp.p

Abbreviations: NS idiopathic nephrotic syndrome, MesPGN mesangial proliferative glomerulonephritis, FSGS focal segmental glomerulosclerosis, GR glucocorticoid receptor, Hsp heat shock protein, GRE glucocorticoid response element, NR3C1, nuclear receptor subfamily 3 , group $C$, member 1 , SNP single nucleotide polymorphisms, IPO13 importin 13, MIF macrophage migration inhibitory factor, JIA juvenile idiopathic arthritis, ALU acute lung injury, CYP cytochrome P, IBD inflammatory bowel disease, IL interleukin, ABCB1 ATP-binding cassette subfamily B member 1, GLCCI1 glucocorticoid-induced transcript 1 gene 


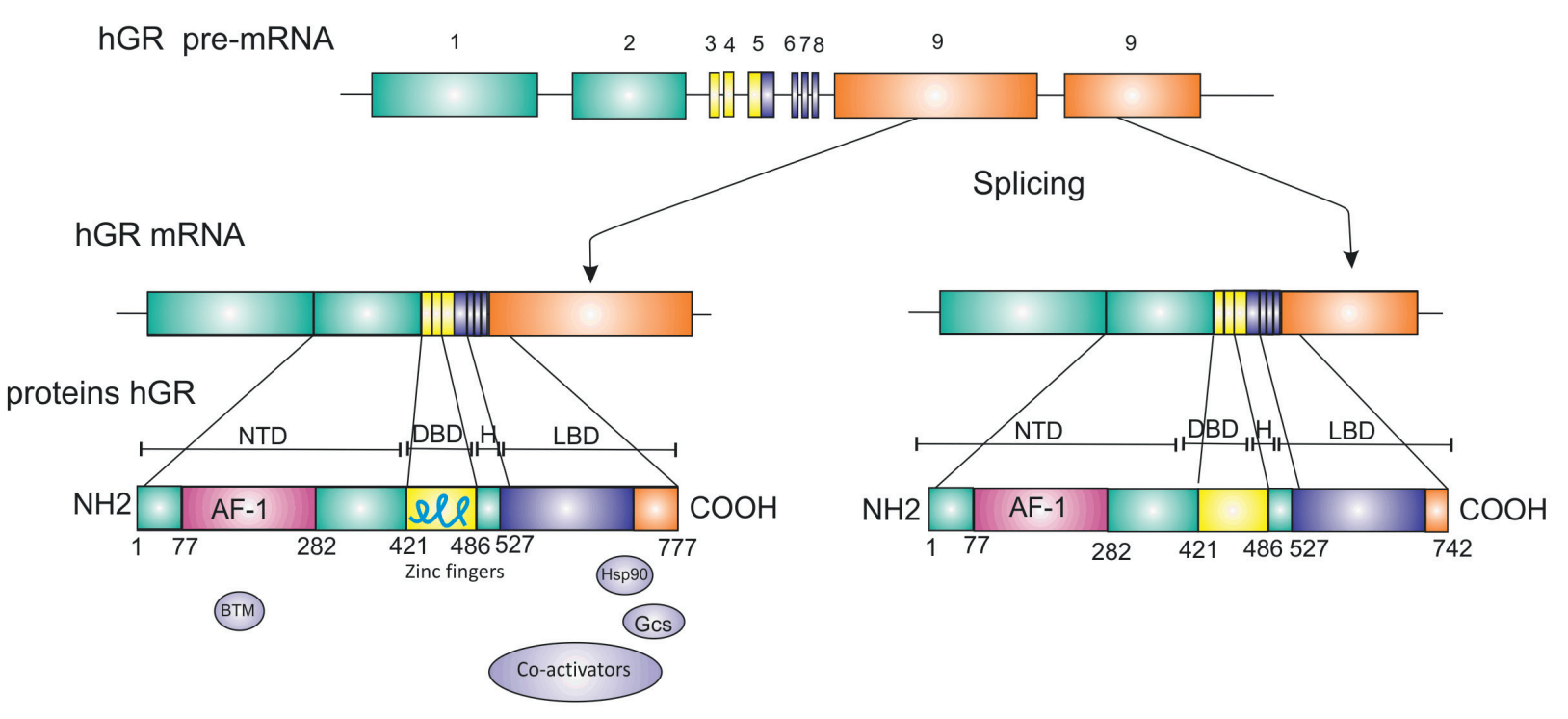

Figure 1. Structure of GR and formation of its two isoforms, $\alpha$ and $\beta$ due to alternate splicing.

NTD, N-terminal transactivation domain; $\mathrm{H}$, hinge; DBD, DNA binding domain; LBD, C-terminal ligand binding domain; GCs, glucocorticoids; hGR mRNA, human glucocorticoid receptor mRNA; hGR pre-mRNA, human glucocorticoid receptor pre-mRNA; AF-1, activation function-1.

and binds to specific DNA regions, the so called GREs (glucocorticoid response elements) or, as a monomer, to other transcription factors (a direct protein-protein interaction) (Croxtall et al., 2002; De Iudicibus et al., 2011; Lu et al., 2004) (Fig. 2).

Binding of the recetor to GRE may induce activation of genes, leading to an increased transcription of several anti-inflammatory genes, such as those encoding annexins, interleukin 10 (IL10), inhibitor of nuclear factor kappa B (ikB). The process is termed transactivation $(\mathrm{Lu}$ et al., 2004). Processes involving inhibition of gene activity, such as silencing of osteocalcin or prolactin genes due to binding to negative GRE are also possible but they are of no key importance for the anti-inflammatory role of glucocorticoids (Alangari, 2010). Reichardt et al. (1998) demonstrated that the activity of GR is not restricted to binding with GRE. They provided evidence for a direct action of GR. In the experiment with GR ${ }^{\mathrm{dim} /}$ dim mice, carrying a A458T point mutation within the dimerization-driving loop, the absence of dimerization and, thus, the absence of binding to GRE did not prevent GR from entering into functional reactions with transcription factors, such as AP-1 or NFKB (nuclear factor kappa B). This resulted in the attainment of maturity by the mice (Barnes, 1998; Croxtall et al., 2002).

\section{NON-GENOMIC MECHANISMS OF GLUCOCORTICOID ACTIVITY}

The non-genomic activity of glucocorticoids is manifested by a rapid effect (within seconds or minutes) of short duration (60-90 minutes), as compared to their genomic activity, but the time relationship is dependent on the dose of glucocorticoids (Alangari, 2010). The mechanism involves an interaction with cell membrane, effects resulting from binding of the cytosolic glucocorticoid receptor to the cell membrane and from binding of glucocorticoids to the receptor present in the cell membrane (Alangari, 2010; Stahn et al., 2008).

In higher concentrations glucocorticoids, through lipid peroxidation, may affect the properties of membranes leading to their increased permeability. This may be fol-

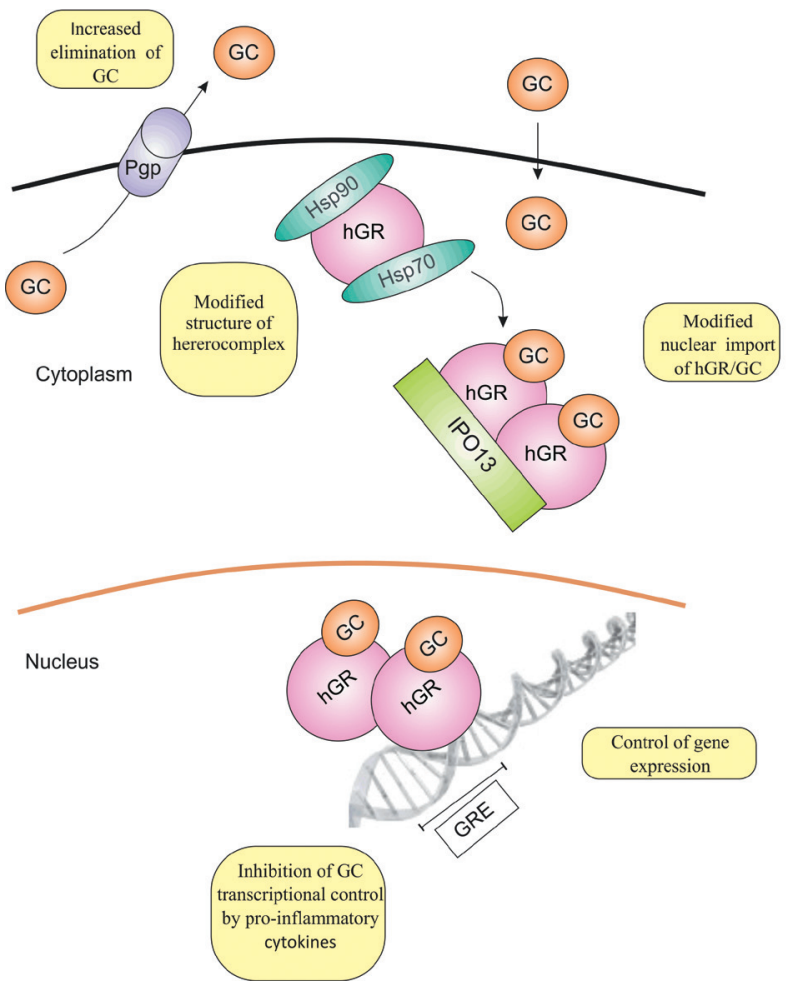

Figure 2. Mechanism of glucocorticoid action and factors engaged in development of steroid resistance according to De ludicibus et al. (2011) modified.

IPO13, importin 13; hGR, human glucocorticoid receptor; GC, glucocorticoid; GRE, glucocorticoid response element; Pgp, glycoprotein $\mathrm{P} ; \mathrm{Hsp} 90$, heat shock protein 90.

lowed by alterations in ion transport across the membrane and changes in cellular production of ATP. The effects result in the inhibition of inflammatory cell function (Alangari, 2010). Interaction of glucocorticoids with membrane-incorporated cytosolic GR may be followed by inhibition of the release of arachidonic acid from 
membrane phospholipids; arachidonic acid acts as a mediator of cell growth and inflammatory reactions (Alangari, 2010; Stahn et al., 2008). Effects of non-genomic activity of glucocorticoids are also linked to their interaction with membranous GR (mGR), supposed to represent an alternative form of GR, arising due to alternate splicing, post-translational processing or a distinct promoter (Bartholome et al., 2004).

\section{GENETIC FACTORS}

The mechanisms of glucocorticoid action sheds some light on the potential causes due to which steroid resistance may develop in treatment of autoimmune diseases. Currently, extensive attention is devoted to the search for genetic variables which might explain ineffective steroid therapy in idiopathic nephrotic syndrome (Table 1).

The key element in the molecular mechanism of glucocorticoid action seems to involve GR. Mutations in the GR gene (NR3C1, nuclear receptor subfamily 3, group $C$, member 1) may result in steroid resistance. Also several polymorphisms were identified, which were linked to the disease (De Iudicibus et al., 2011; Mwinyi et al., 2010; Ouyang et al., 2012). In association with this, in recent years the term "Chrousos syndrome" appeared: a rare, familial or sporadic syndrome linked to mutation in the NR3C1 receptor gene, characterized by insensitivity to glucocorticoids due to reduced expression or absence of functional GR, and by elevated levels of adrenocorticotropic hormone (ACTH) (De Iudicibus et al., 2011). Among the examined polymorphisms in the NR3C1 gene, three proved to be functionally significant: they were linked to reduced sensitivity to both endogenous and exogenous glucocorticoids and could be potential causes of steroid resistance. They included the following polymorphisms: TthIIII (rs10052957) - with a substitution of $\mathrm{C}>\mathrm{T}$ in the promoter region, ER22/23EK (rs6189/rs6190) in the N-terminal transactivation domain, a two nucleotide substitution in codons 22 and 23 of exon 2, GR-9 (rs6198) in 3'UTR (3'-untranslated region), and an ATTTA sequence altered to GTT'TA in exon 9 $\beta$. On the other hand, two polymorphisms, N363S (rs6195) - exon 2, a substitution of AAT $>$ AGT, resulting in a substitution of Asp- $>$ Ser in codon 363, and BclI (rs41423247) — intron 2, with a substitution of $C>G$, were linked to an increased sensitivity to glucocorticoids (De Iudicibus et al., 2011; Gross et al., 2009; Mwinyi et al., 2010; van Rossum \& Lamberts, 2006).

Components of the GR heterocomplex were also examined, including heat shock proteins 90 (Hsp90), which act as important molecular chaperones for GR and are assumed to be of key importance for the control of glucocorticoid effects (Gross et al., 2009; Ouyang et al., 2012). Earlier studies demonstrated that both expression and nuclear distribution of Hsp90 were augmented in steroid-resistant patients with idiopathic nephrotic syndrome. Ouyang et al. (2012) activated the expression of total Hsp90 in peripheral blood mononuclear cells by exposing them to interleukin 6 (IL6) in vitro and showed that their nuclear level of Hsp90, the binding of GR to DNA, and the activity of apoptotic cells remained unaltered. Moreover, an increased level of nuclear Hsp90 was mainly due to its binding to GR in the cell nucleus while GR binding to DNA decreased markedly in patients with steroid resistant nephrotic syndrome. This indicates that accumulation of nuclear Hsp90 potentially decreases the ability of GR to bind DNA and activate transcription, which may induce resistance to steroid therapy in patients with nephrotic syndrome (Ouyang et al., 2012). An altered level of Hsp90 was identified also in peripheral blood mononuclear cells in patients with steroid-resistant asthma or multiple sclerosis (Gross et al., 2009). Single nucleotide polymorphisms (SNPs) were also examined in the Hsp90 encoding gene (HSPCA coding for hsp90-1 $\alpha$, HSPCB coding for hsp90-1 $\beta$ ). However, in adults with asthma, no correlation could be demonstrated between SNPs in HSPCA (3'-UTR+307, rs3736807, rs4906178, rs3809386, promoter -32) or HSPCB (rs504697 and rs3757286) genes on one hand and the response to treatment on the other (De Iudicibus et al., 2011).

In the mechanism of glucocorticoid action a significant role is played also by nuclear translocation recep-

Table. 1. Factors engaged in development of steroid resistance.

\begin{tabular}{ll}
\hline Factor & Mechanism \\
\hline GR & Mutations and polymorphism of $N R 3 C 1$ gene \\
\hline Heterocomplex of GR & Polymorphism of $H S P 90$ gene \\
\hline Nuclear receptors of translocation & Polymorphisms of importin 13 gene (IPO13) \\
\hline Pro- and anti-inflammatory factors & Involvement of cytokines, including MIF, IL4,IL6,TNF- $a$ \\
\hline Glucocorticoid-induced transcript 1 protein & Polymorphisms in GLCCI1gene \\
\hline Glycoprotein P & Polymorphisms of $A B C B 1$ (MDR1) gene \\
\hline Cytochrome P450 & Altered expression of $A B C B 1$ under effect of pro-inflammatory cytokines \\
\hline
\end{tabular}


tors, which are responsible for the effective transport of GR to the cell nucleus. They include importin-13 (IPO13), which mediates the import of GR to cell nucleus. Raby et al. (2009) examined genetic variants of IPO13 in children with benign or moderate asthma treated with inhaled anti-inflammatory agents, including glucocorticoids, such as budesonid or nedocromil. The detected polymorphisms in the IPO13 gene were found to affect the reactivity of the respiratory tract, influencing the bioavailability of glucocorticoids in childhood asthma (Raby et al., 2009).

A significant involvement of several pro-inflammatory cytokines, including macrophage migration inhibitory factor (MIF) was also documented. MIF is produced mainly by $\mathrm{T}$ lymphocytes, but also by epithelial and endothelial cells and it plays an important role in securing innate immune resistance of the organism (Berdeli et al., 2005). However, due to the broad range of action of the cytokine it also represents a critical mediator in many inflammatory and autoimmune diseases, such as septic shock, juvenile idiopathic arthritis (JIA), ulcerative colitis, pneumonia, type I diabetes mellitus, glomerulonephritis or tumours (Berdeli et al., 2005; Stosic-Grujicic et al., 2009; Vivarelli et al., 2008). In contrast to other proinflammatory cytokines, which — in general — are suppressed by glucocorticoids, expression and secretion of MIF increase in response to physiological concentrations of glucocorticoids. On the other hand, during treatment of autoimmune diseases, MIF counteracts the effects of glucocoricoids by re-establishing production of cytokines by macrophages and by activating $\mathrm{T}$ lymphocytes. Based on this, it is concluded that MIF represents a factor which is induced by glucosteroids and, in parallel, leads to inhibition of their efficacy (Bucala, 2012; Stosic-Grujicic et al., 2009). In this way inhibition of MIF seems to represent an effective tool in the treatment of many autoimmune diseases, including patients manifesting resistance to standard therapy with glucocorticoids (Berdeli et al., 2005, Stosic-Grujicic et al., 2009). Since it is assumed that polymorphisms in immune response genes may be a cause of many inflammatory and autoimmune diseases and that they may exhibit a prognostic value, polymorphisms of the MIF gene were examined. Baugh et al. (2002) identified a polymorphism in short tandem repeats within the MIF gene and found it to be linked to reduced activity of its promoter; a homozygous form of a specific genotype was demonstrated to be associated with a lowered risk of rheumatoid arthritis. The polymorphism involved the number of repeats of the CAT'T sequence in position -791 of the promoter, where the allele of 5 CAT'T repeats manifested the lowest activity of the promoter and it was the least effective in stimulating MIF promoter in vitro. Low expression of the allele with 5 CAT'T repeats correlated with low intensity of inflammation in rheumatoid arthritis. The presence of the $-173 \mathrm{G} / \mathrm{C}$ SNP (rs755622) in the MIF gene promoter was also analysed but no significant association with the disease was found (Baugh et al., 2002). Shiroeda et al. (2010) examined functional polymorphisms in the MIF gene promoter in ulcerative colitis. In this case the $5 / 5$ CAT'T genotype was found to be linked to a lower risk of ulcerative colitis (UC). In addition, the 7/7-CATT genotype was found to be strongly linked to UC phenotype in the distal colon and to chronically persistent disease. No such relationship could be detected in the case of the G-173-C polymorphism. Therefore, the authors suggested that the four nucleotide CATT repeat within the MIF gene promoter may be linked to development of UC and to advancement of inflammation in UC pa- tients (Shiroeda et al., 2010). Gao et al. (2007) examined MIF in acute lung injury (ALI), studying patients with sepsis or ALI-induced sepsis. In reference to Donn et al. (2002), who detected association between the $-173 \mathrm{C}$ allele and JIA, Gao et al. (2007) also found a significant linkage between the CC genotype of the rs755622 polymorphism and an increased risk of sepsis development and pointed to the correlation between the polymorphism and microsatellite CAT'T repeats. Berdeli et al. (2005) examined the $-173 \mathrm{G} / \mathrm{C}$ polymorphism in children with an idiopathic nephrotic syndrome who failed to react to steroid therapy. The $\mathrm{C}$ allele proved to be strongly linked to steroid resistance in INS and a correlation was disclosed with histopathology characteristic for FSGS and IgM nephropathy. Moreover, Vivarelli et al. (2008) demonstrated a relationship between polymorphism of the $-173 \mathrm{C}$ allele in the MIF gene promoter in steroid-resistant children with INS. The studies on MIF related to steroid resistance suggest that in such cases alternative therapies should be attempted, including treatment with MIF-specific antibodies (Berdeli et al., 2005; Bucala, 2012; Vivarelli et al., 2008).

It was shown that SNPs in the promoter region of the glucocorticoid-induced transcript 1 gene (GLCCI1) were responsible for steroid resistance in asthmatic patients and were associated with a decreased level of expression in lymphoblastoid B cells. Because of reports that GLCCI1 is expressed in podocytes and mesangial cells in the kidney and suggestions that the loss of this protein may be correlated with the dysfunction of the filtration barrier, Cheong et al. (2012) examined GLCCI1 gene polymorphisms in pediatric NS, including SR and SS patients, in the Korean population. They analysed two SNPs in the promoter region: rs37972 and rs3797, which were correlated with renal biopsy. However, they did not observe any association with steroid-responsiveness. It may suggest limitations of studies conducted on patients of one nationality and it shows that the function of GLCC1 at the cellular level is still not well determined (Cheong et. al., 2012).

\section{FARMACOKINETICS}

Metabolizing enzymes and cellular pumps are fully engaged in pathways leading to elimination of several drugs. The most important of them include glycoprotein-P, the principal transporter eliminating xenobiotics, exporting drugs from the cell, and cytochrome P450 (CYP), which metabolizes several exo- and endogenous components. Both glycoprotein P and cytochrome P450 are expressed in lymphocytes, in cells of intestinal epithelium, in liver. They are engaged in transport and metabolism of glucocorticoids (De Iudicibus et al., 2011).

A significant expression of glycoprotein $\mathrm{P}$ was detected in circulating lymphocytes and in epithelial cells in patients with Crohn disease (CD), in patients with UC with resistance to glucocorticoids and in patients with inflammatory bowel disease (IBD) but the relationship between administration of glucocorticoids and expression of glycoprotein $\mathrm{P}$ was described only in monocytes of patients with IBD. Therefore, it remains unknown whether increased glycoprotein $\mathrm{P}$ expression is linked to IBD or if it represents a secondary effect of therapy with glucocorticoids (De Iudicibus et al., 2011). Glycoprotein $\mathrm{P}$ is encoded by the MDR1 gene (ABCB1ATP - binding cassette, sub-family $\mathrm{B}$, member 1 ) located on human chromosome 7q21.12. Polymorphisms of the MDR1 gene were examined in SR and SS children with INS. 
Jafar et al. (2011) examined three exon polymorphisms in the MDR1 gene: G3435T, G2677T/A and C1236T in a population of Indian children with nephrotic syndrome and found that the homozygosity for the polymorphisms in exon 26 G3435T (TT versus $\mathrm{CC}$ ) and in exon 26 G2677T/A (T'T+AA versus GG) was observed much more frequently in nephrotic children than in the control and, in addition, that these polymorphisms were linked to the development of SRNS. In a similar manner Choi et al. (2011) and Wasilewska et al. (2006, 2007) presented results indicating involvement of the polymorphisms in the development of steroid resistance in children with NS. Krupoves et al. (2011) pointed to the relationship between the G3435T polymorphism in the ABCB1 gene and results of treatment with corticoids in patients with CD. In addition, Yossef et al. (2011) examined the relationship between serum IL2 content and the level of MDR1 gene expression and found that high IL2 content correlated with high expression of the MDR1 gene in lymphocytes of patients with SRNS. This pointed to elimination of glucocorticoids by glycoprotein $\mathrm{P}$ as a possible cause of steroid resistance. This finding is in agreement with a previous report by Stachowski (2000), which showed that the activity of Th1 cells, based on the production of IL 2 and IFN- $\gamma$, was higher in steroid resistant children from the Polish population with NS. Furthermore, the high expression of the MDR1 gene was observed in SRNS patients. This mechanism resulted in higher activity of the P-gp export pump in steroid therapy, whereas in the SSNS, CSNS (cyclophosphamide sensitive nephrotic syndrome) and CsASNS (cyclosporine sensitive nephrotic syndrome) groups the expression and activity of MDR1 were at a low level compared to SRNS and controls. Chiou et al. (2012) documented the link between the C1236T polymorphism in the $A B C B 1$ gene and steroid resistance in the Chinese population.

Human cytochrome P450 (CYP) comprises several isoforms. In humans, the CYP family includes CYP1, CYP2, CYP3, CYP4, CYP5, CYP7, CYP8, CYP11 and CYP17. The subfamily 3A of human cytochrome P450 (CYP3A) plays a significant role in drug metabolism. The four genes of CYP3A: CYP3A5, CYP3A7,CYP3A4 and $C Y P 3 A 43$ are located on chromosome $7 q 22.1$ (De Iudicibus et al., 2011, Chiou et al., 2012). Chiou et al. (2012) analysed the A6986G polymorphism in the CYP3 A5 gene in INS patients, both steroid-sensitive (SS) and steroid-resistant (SR), subjected to therapy with prednisolone. Even if the frequency of the $G$ allele was relatively higher in SR than in SS patients (the difference proved to be insignificant), the result may point to the potential involvement of the polymorphism in the development of steroid resistance.

Among potential factors engaged in the development of steroid resistance, polymorphisms in cytokine genes should be mentioned, especially in IL-4, IL-6, TNF- $\alpha$ (tumor necrosis factor-alpha) genes, where TNF- $\alpha$ represents a pro-inflammatory cytokine while IL-4 and IL-6 are anti-inflammatory cytokines. Pro-inflammatory cytokines are important in $\mathrm{T}$ and $\mathrm{B}$ lymphocytes as they initiate immune responses (Barnes, 1998; Jafar et al., 2011; Yang et al., 2012). Jafar et al. (2011) demonstrated correlations between polymorphisms in IL-6, G174C (rs1800795), IL-4, C590T(rs2243250), TNF- $\alpha$, G308A (rs1800629) and NS as well as their marked role in diagnosis of SRNS. In addition, the IL-4 polymorphism correlated with predisposition to the minimal change nephrotic syndrome (Jafar et al., 2011; Kobayashi et al., 2003).

\section{SUMMARY}

As indicated by many literature data, patients with classical syndrome of resistance to treatment with corticosteroids manifest a quite variable phenotypic pattern. In addition, the clinical scope of the syndrome is very broad. Apart from its correlation with nephrotic syndrome it accompanies multiple diseases, such as asthma, rheumatoid arthritis, Crohn disease, Cushing disease, autoimmune hepatitis, blood neoplastic diseases, sepsis. This makes the diagnosis difficult and it requires additional tests as well as searches for heritable links. High hopes are linked to genetics and pharmacogenomics. Until now, the investigators succeded in examining several polymorphisms in key genes of molecular pathways linked to glucocorticoid actions, such as NR3C1, HSPCA, HSPCB, IPO13, CYP, MIF, ABCB1, IL6, IL4, TNF, but the results point only to the potential background of the syndrome. Data obtained so far indicate the need for additional investigations, search for new mutations and, perhaps, for epigenetic studies.

\section{Acknowledgements}

We wish to acknowledge the assistance of Dr. Jan Jaroszewski.

Financial support: supported by grant no. N N401 528140 from the Polish Ministry of Science and Higher Education and NR 13 0033 10/2010 State Committee for Scientific Research, NCBR.

\section{REFERENCES}

Alangari AA 2010 Genomic and non-genomic actions of glucocorticoids in asthma. Ann Thorac Med 5: 133-139.

Banaszak B, Banaszak P, Adamczyk P, Ziora K (2011) First detection of pediatric nephrotic syndrome: clinical characteristics of a steroidsensitive and steroid-resistant patient. Przegl Pediatr 41: 147-151 (in Polish).

Barnes PJ (1998) Anti-inflammatory actions of glucocorticoids: molecular mechanism. Clin Sci 94: 557-572.

Bartholome B, Spies CM, Gaber T, Schuchmann S, Berki T, Kunkel D, Bienert M, Radbruch A, Burmester GR, Lauster R, Scheffold A, Buttgereit F (2004) Membrane glucocorticoid receptors (mGCR) are expressed in normal human peripheral blood mononuclear cells and up-regulated after in vitro stimulation and in patients with rheumatoid arthritis. FASEB J 18: 70-80.

Baugh JA, Chitnis S, Donnelly SC, Monteiro J, Lin X, Plant BJ, Wolfe F, Gregersen PK, Bucala R (2002) A functional promoter polymorphism in the macrophage migration inhibitory factor (MIF) gene associated with disease severity in rheumatoid arthritis. Genes Immun 3: $170-176$.

Berdeli A, Mir S, Ozkayin N, Serdaroglu E, Tabel Y, Cura A (2005) Association of macrophage migration inhibitory factor $-173 \mathrm{C}$ allele polymorphism with steroid resistance in children with nephrotic syndrome. Pediatr Nephrol 20: 1566-1571.

Bucala R (2012) MIF, MIF Alleles, and prospects for therapeutic intervention in autoimmunity. J Clin Immunol [Epub ahead of print].

Cheong HI, Kang HG, Schlondorff J (2012) GLCCI1 single nucleotide polymorphisms in pediatric nephrotic syndrome. Pediatr Nephrol 27: 1595-1599.

Chiou YH, Wang LY, Wang TH, Huang SP (2012) Genetic polymorphisms influence the steroid treatment of children with idiopathic nephrotic syndrome. Pediatr Nephrol 27: 1511-1517.

Choi HJ, Cho HY, Ro H, Lee SH, Han KH, Lee H, Kang HG, Ha IS, Choi Y, Cheong HI (2011) Polymorphisms of the MDR1 and MIF genes in children with nephrotic syndrome. Pediatr Nephrol 26: 1981-1988.

Croxtall JD, van Hal P'T, Choudhury Q, Gilroy DW, Flower RJ (2002) Different glucocorticoids vary in their genomic and non-genomic mechanism of action in A549 cells. Br J Pharmacol 135: 511-519.

De Iudicibus S, Franca R, Martelossi S, Ventura A, Decorti G (2011) Molecular mechanism of glucocorticoid resistance in inflammatory bowel disease. World J Gastroenterol 17: 1095-1108.

Donn R, Alourfi Z, De Benedetti F, Meazza C, Zeggini E, Lunt M, Stevens A, Shelley E, Lamb R, Ollier WE, Thomson W, Ray D; British Paediatric Rheumatology Study Group (2002) Mutation screening of the macrophage migration inhibitory factor gene: posi- 
tive association of a functional polymorphism of macrophage migration inhibitory factor with juvenile idiopathic arthritis. Arthritis Rheum 46: 2402-2409.

Gao L, Flores C, Fan-Ma S, Miller EJ, Moitra J, Moreno L, Wadgaonkar R, Simon B, Brower R, Sevransky J, Tuder RM, Maloney JP, Moss M, Shanholtz C, Yates CR, Meduri GU, Ye SQ, Barnes KC, Garcia JG (2007) Macrophage migration inhibitory factor in acute lung injury: expression, biomarker, and associations. Transl Res 150: 18-29.

Gross KL, Lu NZ, Cidlowski JA (2009) Molecular mechanisms regulating glucocorticoid sensitivity and resistance. Mol Cell Endocrinol 300: $7-16$.

Heitzer MD, Wolf IM, Sanchez ER, Witchel SF, DeFranco DB (2007) Glucocorticoid receptor physiology. Rev Endorr Metab Disord 8: 321330.

Jafar T, Agrawal S, Mahdi AA, Sharma RK, Awasthi S, Agarwal GG (2011) Cytokine gene polymorphism in idiopathic nephrotic syndrome children. Indian J Clin Biochem 26: 296-302.

Jafar T, Prasad N, Agarwal V, Mahdi A, Gupta A, Sharma RK, Negi MP, Agrawal S (2011) MDR-1 gene polymorphisms in steroidresponsive versus steroid-resistant nephrotic syndrome in children. Nephrol Dial Transplant 26: 3968-3974.

Jaroniec M, Ostalska-Nowicka D, Śmiech M, Siwińska A, Zachwieja J, Nowicki M (2010) Evcaluation of single nucleotide polymorphism in direct vicinity of recognised mutations in NPHS2 gene in children with nephrotic syndrome. Nefrol Dial Pol 14: 111-115 (in Polish).

Kobayashi Y, Arakawa H, Suzuki M, Takizawa T, Tokuyama K, Morikawa A (2003) Polymorphisms of interleukin-4-related genes in Japanese children with minimal change nephrotic syndrome. Am J Kidney Dis 42: 271-276.

Krupoves A, Mack D, Seidman E, Deslandres C, Amre D (2011) Associations between variants in the ABCB1 (MDR1) gene and corticosteroid dependence in children with Crohn's disease. Inflamm Bowel Dis 17: 2308-2317.

Lu NZ, Cidlowski JA (2004) The origin and functions of multiple human glucocorticoid receptor isoforms. Ann N Y Acad Sci 1024: $102-123$.

Mwinyi J, Wenger C, Eloranta JJ, Kullak-Ublick GA (2010) Glucocorticoid receptor gene haplotype structure and steroid therapy outcome in IBD patients. World J Gastroenterol 16: 3888-3896.

Ouyang J, Chen P, Jiang T, Chen Y, Li J (2012) Nuclear HSP90 regulates the glucocorticoid responsiveness of PBMCs in patients with idiopathic nephrotic syndrome. Int Immunopharmacol 14: 334-340.

Raby BA, Van Steen K, Lasky-Su J, Tantisira K, Kaplan F, Weiss ST (2009) Importin-13 genetic variation is associated with improved airway responsiveness in childhood asthma. Respir Res 10: 67.

Reichardt HM, Kaestner KH, Tuckermann J, Kretz O, Wessely O, Bock R, Gass P, Schmid W, Herrlich P, Angel P, Schütz G (1998) DNA binding of the glucocorticoid receptor is not essential for survival. Cell 93: 531-541.
Shiroeda H, Tahara T, Nakamura M, Shibata T, Nomura T, Yamada H, Hayashi R, Saito T, Yamada M, Fukuyama T, Otsuka T, Yano H, Ozaki K, Tsuchishima M, Tsutsumi M, Arisawa T (2010) Association between functional promoter polymorphisms of macrophage migration inhibitory factor (MIF) gene and ulcerative colitis in Japan. Cytokine 2: 173-177.

Smoak KA, Cidlowski JA (2004) Mechanisms of glucocorticoid receptor signaling during inflammation. Mech Ageing Dev 125, 697-706.

Stachowski J, Krynicki T, Barth C, Runowski D, Lewandowska-Stachowiak M, Warzywoda A, Bortkiewicz E, Dobosz M, Maciejewski J (2000) Does the changed Th1/Th2 activity in children with the assessment of body water in children with nephrotic syndrome: initial results. Pol Merkur Lekarski 8: 222-224.

Stachowski J, Zanker CB, Runowski D, Zaniew M, Peszko A, Medyńska A, Zwolińska D, Rogowska-Kalisz A, Hyla-Klekot L, Szprygner K, Weglarska J, Sieniawska M, Musiał W, Maciejewski J, Baldamus CA (2000) Resistance to therapy in primary nephrotic syndrome: effect of MDR1 gene activity. Pol Merkur Lekarski 8: 218-221.

Stahn C, Buttgereit F (2008) Genomic and nongenomic effects of glucocorticoids. Nat Clin Pract Rheumatol 4: 525-533.

Stosic-Grujicic S, Stojanovic I, Nicoletti F (2009) MIF in autoimmunity and novel therapeutic approaches. Autoimmun Rev 8: 244-249.

Taraszkiewicz J, Hyla Klekot L, Wystrychowski A (2009) Idiopathic nephrotic syndrome with minimum lesions: pathogenetic aspects yesterday and today. Nefrol Dial Pol 13: 244-249 (in Polish).

Urban JD, Budinsky RA, Rowlands JC (2012) An evaluation of single nucleotide polymorphisms in the human heat shock protein $90 \mathrm{kDa}$ alpha and beta isoforms. Drug Metab Pharmacokinet 27: 268-278.

van Rossum EF, Lamberts SW (2006) Glucocorticoid resistance syndrome: A diagnostic and therapeutic approach. Best Pract Res Clin Endocrinol Metab 20: 611-626.

Vivarelli M, D’Urbano LE, Stringini G, Ghiggeri GM, Caridi G, Donn R, Tozzi A, Emma F, De Benedetti F (2008) Association of the macrophage migration inhibitory factor $-173^{*} \mathrm{C}$ allele with childhood nephrotic syndrome. Pediatr Nephrol 23: 743-748.

Wasilewska A, Zalewski G, Chyczewski L, Zoch-Zwierz W (2007) MDR-1 gene polymorphisms and clinical course of steroid-responsive nephrotic syndrome in children. Pediatr Nephrol 22: 44-51.

Wasilewska A, Zoch-Zwierz W, Pietruczuk M, Zalewski G (2006) Expression of P-glycoprotein in lymphocytes from children with nephrotic syndrome, depending on their steroid response. Pediatr Nephrol 21: 1274-1280.

Yang N, Ray DW, Matthews LC (2012) Current concepts in glucocorticoid resistance. Steroids 77: 1041-1049.

Youssef DM, Elbehidy RM, Abdelhalim HS, Amr GE (2011) Soluble interleukine-2 receptor and MDR1 gene expression levels as inflammatory biomarkers for prediction of steroid response in children with nephrotic syndrome. Iran J Kidney Dis 5: 154-161. 